\title{
Fibromyalgia Possibly the Result of Calcium Deficiency by Amos Gelbard
}

\section{Gelbard A*}

Zefat Academic College, Israel

*Corresponding author: Amos Gelbard, Zefat Academic College, Israel, E-mail amosgelbard@gmail.com

Keywords: Fibromyalgia; Calcium

Fibromyalgia symptoms include pain and weakness in the muscles and joints, in movement, and a physical and emotional fatigue.

Calcium is the main content in bones and joints and intracellular, free Calcium has an important role in muscle contraction.

Calcium Deficiency, as a medical condition, also has many of the same symptoms and characteristics as Fibromyalgia.

Several studies have shown significantly lower concentrations of intracellular Calcium in Fibromyalgia patients [1-4].

These studies and the knowledge of Calcium's role in muscle contraction lead to the assumption that Calcium deficiency could be the cause of the well known symptoms of Fibromyalgia.

It's therefore sensible to suggest that treating Fibromyalgia with Calcium, either by diet or food supplementation, should be examined as a possible cure for this disease.

\section{References}

1. Kim YS, Kim KM, Lee DJ, Kim BT, Park SB, et al. (2011) Women with Fibromyalgia Have Lower Levels of Calcium, Magnesium, Iron and Manganese in Hair Mineral Analysis. J Korean Med Sciv 26(10): 12531257.

2. Magaldi M, Moltoni L, Biasi G, Marcolongo R (2000) Role of intracellular calcium ions in the physiopathology of fibromyalgia syndrome. Bollettino Della Societa Italiana di Biologia Sperimentale 76(12): 1-4.

3. Ng SY (1999) Hair calcium and magnesium levels in patients with fibromyalgia: a case center study. J Manipulative Physiol Ther 22(9): 586-593.

4. Neeck G, Riedel W (1992) Thyroid function in patients with fibromyalgia syndrome. Department of Rheumatology and Physical Medicine, University of Giessen, Bad Nauheim, Germany. The Journal of Rheumatology 19(7): 1120-1122. 